\title{
Quantification of Material Wastage in Construction Industry of Pakistan: An Analytical Relationship between Building Types and Waste Generation
}

\author{
"Husnain Arshad', Muhammad Qasim', Muhammad Jamaluddin \\ Thaheem' and Hamza Farooq Gabriel ${ }^{2}$
}

\begin{abstract}
Published online: 15 January 2018
To cite this article: Husnain Arshad, Muhammad Qasim, Muhammad Jamaluddin Thaheem and Hamza Faroog Gabriel. (2017). Quantification of material wastage in construction industry of Pakistan: An analytical relationship between building types and waste generation. Journal of Construction in Developing Countries, 22(2): 19-34. https://doi.org/10.21315/ jcdc2017.22.2.2
\end{abstract}

To link to this article: https://doi.org/10.21315/jcdc2017.22.2.2

\begin{abstract}
The construction industry consumes a large part of raw material and global energy, and produces huge amount of solid waste. It is established that waste generated by construction processes has significant negative impact on the economy and environment. Effective waste management helps in reducing quantity of wastes and making a substantial contribution towards sustainable development and cost control. Based on a benchmarking approach, this research quantifies the material wastage and its causes in different types of building projects. In a waste diagnostic survey, 38 project sites were surveyed. Results revealed that bricks, tiles, and plaster from mortar are the most wasteful materials, and improper worker's skills, poor supervision, and lack of management the most significant causes. Buildings with substantial architectural works tend to generate maximum amount of waste while contractor size does not affect waste generation rate. Based on expert opinion, practical recommendations are given to control material waste. The findings offer a new perspective on sustainable construction by correlating building types with waste generation, as contribution to the existing body of knowledge. It will lead the construction managers to better understand the actual situation of construction waste and devise control measures.
\end{abstract}

Keywords: Construction waste, Cause identification, Construction material, Waste reduction, Sustainable construction

\section{INTRODUCTION}

Building construction consumes $40 \%$ of global energy, contributes $5 \%-15 \%$ towards GDP, and offers 5\%-10\% of employment (Division of Technology, Industry and Economics [DTIE], 2009). At the same time, it consumes $40 \%$ of the world's raw materials (Sharma et al., 2011). According to the American Institute of Architects (AIA) Sustainability Discussion Group (2008), $25 \%$ to $40 \%$ of total waste comes from building construction, which impacts the environment severely. European Commission in July 2014 formally adopted the proposal for reuse and recycling of up to $50 \%$ of municipal waste till 2020 and increase it to $70 \%$ till 2030 . However, building material waste is difficult to reuse due to large degree of heterogeneity. The large amount of solid waste generated by the construction industry is becoming a pressing

\footnotetext{
'Department of Construction Engineering and Management, NIT-SCEE, National University of Sciences and Technology, Islamabad, PAKISTAN

${ }^{2}$ Institute of Civil Engineering, SCEE, National University of Sciences and Technology, Islamabad, PAKISTAN

"Corresponding email: husnain.cem06@nit.nust.edu.pk
} 
issue in many cities of the world (Begum et al., 2006). Thus, sustainability goals and performance of construction industry are challenged by the huge amount of solid waste (Kulatunga et al., 2006).

Economic development of any country largely depends on building construction. A lot of waste occurs during the construction, which causes a huge loss to economy and environment (Kulatunga et al., 2006). Furthermore, rising cost of projects and competitive bidding have made it essential for contracting firms to take serious action to reduce construction waste as profit margins are becoming narrower with every passing day (EC Harris LLP, 2013). Enshassi, Al-Hallaq and Mohamed (2006) ranked material wastage as one of the major causes of contractor's business failure in developing countries. The reduction in construction waste can significantly help in increasing total profit and gaining economic stability for a country and construction firms. Project managers and construction staff usually fail to control the waste in construction projects and identify the root causes of waste generation due to absence of appropriate tools to measure it (Li et al., 2005). Construction waste is considerable where poor management is a norm (Nagapan, Abdul Rahman and Asmi, 2011). Site staff and project manager can reduce the construction waste with efficient management (Kulatunga et al., 2006). However, what cannot be measured cannot be managed. Unfortunately, in the context of Pakistani construction industry, there is no study on quantification of construction material waste.

It is opportune to observe that construction industry of Pakistan is vast; it is one of the largest sectors of the economy and shares approximately $2.3 \%$ of the country's GDP. A countable number of material industries are associated with the construction process. According to Haseeb et al. (2011), building construction in Pakistan has a significant role in overall progress of the country by providing widespread employment, bringing foreign investment, delivering housing to the nation, contributing to the growth of other industries by using raw materials from them, and helping in circulation of money within the country. The construction industry is accountable for generating a variety of material waste, the type and amount of which is reliant on different elements such as type of project, common work practices, and the stage of construction.

The current study focuses on quantifying the material wastages, their comparison for different types of buildings and identifying the causes of waste generation to develop awareness and policies through which it can be controlled. It also statistically investigates the waste generation by the size of contracting firm. This study also focuses on practical recommendations in a hope that it may make experts and decision makers aware of the situation of construction waste. One of the practical implications of this study provides the practitioners with hands-on information to devise waste control measures. The scope of this research is restricted to building projects in Pakistan and mainly includes the perception of contractors.

\section{LITERATURE REVIEW}

The term "waste" has been defined in several ways. Waste is any incompetence that results in use of tools, material, labour, equipment, and the capital in larger amount than those measured as essential for the construction. Moreover, waste comprises of material losses and excessive work, produces extra cost to the project but does not add value to the product (Koskela, 1992). Resources, rules, and activities that 
can be eliminated without reducing value for the customer are waste (Polat and Ballard, 2004). Losses from activities that generate indirect or direct waste but do not add value from perspective of the client are waste (Formoso, Isatto and Hirota, 1999). Furthermore, waste refers to anything other than the amount of equipment, material, worker's time, and space necessarily required to add value to the product (Arnold, Chapman and Clive, 2012). The waste at construction site can be grouped into physical and non-physical types (Nagapan, Abdul Rahman and Asmi, 2011). The physical waste includes loss of materials and damages while cost and time overrun refers to non-physical waste. In building material, waste can be described as the difference between total quantity of material brought on site and actual quantity used (Enshassi, 1996; Mcdonald and Smithers, 1998; Shen et al., 2004). This paper focuses only on material wastages without discussing other aspects such as cost and time overrun, as established in lean construction approach.

Material waste in construction has been considered as a major topic for research in the past few years throughout the world (Khanh and Kim, 2014). A number of studies have also been conducted related to the environmental damages as well as on economic aspects of construction wastes (Lee and Lee, 2013). Tam, Shen and Tam (2007) reported an additional cost of $15 \%$ to construction projects cost overruns in UK due to material wastage. Housing construction is responsible for producing varieties of waste concrete, metal, bricks, roofing, wood, drywall, material packaging, plastics, papers, cardboard, and others (Foo et al., 2013). The amount of waste generated is directly proportional to the heavy demands of projects such as housing or residential projects, complexes or hypermarkets and many infrastructure projects required for upgrading the living standards of people (Begum et al., 2006; Nasaruddin, Ramli and Ravana, 2008).

Table 1 is adopted from Chen, Li and Wong (2002) that analysed the mean wastage data categorised into standard materials from specialty contractors from different countries including China, Brazil, UK, USA, Hong Kong, and Korea. It can be deduced that wood is the most wasteful material with an average rate of $22.5 \%$ followed by mortar. Interestingly, mortar's waste rate is unevenly distributed across the sample countries with a maximum standard deviation of 19.3. Although all sample countries do not present data, the least standard deviation is reported for wallpaper with an average waste rate of $10.5 \%$. It is interesting to note that brick/ block is wasted at a rate of $6.1 \%$, which may be true only in the case of developed/ rapidly developing countries only; the underdeveloped or developing countries report a higher rate of brick/block wastage as established in this study.

Furthermore, the waste percentages of different materials in public housing and private residential projects were quantified by Poon, Ann and $\mathrm{Ng}$ (2001). Results revealed that tiles, ready mix cement, bricks, and timber were the most wasteful materials in public housing projects with mean percentage wastage of $6 \%-8 \%, 7 \%$, $6 \%$, and $5 \%$ respectively. Similarly, in private housing projects timber (15\%), plaster from mortar (12\%), ready mix concrete (12\%), and tiles (8\%) were found to be most wasteful materials.

Formoso, Isatto and Hirota (1999) summarised the study of Soibelman (1993) stating that some companies do not focus on material waste; absence of a proper material management policy and waste reduction plan results into generation of onsite waste. A noteworthy portion of waste is caused by complications that occur in stages prior to execution such as inadequate design, lack of planning, flaws in material supply system, etc. (Ekanayake and Ofori, 2004). The waste of building materials is much greater than the minor figures assumed by the companies while estimating cost of the 
project (Saidu and Shakantu, 2015). As previously mentioned, flaws in management are the primary cause of the wastage rather than lack of qualification and inspiration of workers. Regardless of building type, waste generation is a combination of many physical and functional factors such as building size, workmanship, design, planning, etc. and its amount differs from site to site. Moreover, similar sites might show different waste level for the same materials at different stages. It specifies that a significant amount of waste can be controlled (Formoso, Isatto and Hirota, 1999).

Table 1. Average Wastage Rate of Construction Materials on Site in Some Selected Countries

\begin{tabular}{lcccccc}
\hline \multirow{2}{*}{ Material } & \multicolumn{7}{c}{ Mean Wastage (\%) } \\
\cline { 2 - 7 } & USA & China & UK & Korea & Brazil & Hong Kong \\
\hline Blocks/bricks & 3.5 & 2.0 & 4.5 & 3.0 & 17.5 & NA \\
Concrete & 7.5 & 2.5 & 2.5 & 1.5 & 7.0 & 6.7 \\
Drywall & 7.5 & NA & 5.0 & NA & NA & 9.0 \\
Formwork & 10 & 7.5 & NA & 16.7 & NA & 4.6 \\
Glass & NA & 0.8 & NA & 6.0 & NA & 2.3 \\
Mortar & 3.5 & 5.0 & NA & 0.3 & 46.0 & 3.2 \\
Nail & 5.0 & NA & NA & NA & NA & NA \\
Rebar & 5.0 & 5.0 & NA & NA & 21.0 & 8.0 \\
Tile & 6.5 & NA & 5.0 & 2.5 & 87.0 & 6.3 \\
Wallpaper & 10.0 & NA & NA & 11.0 & NA & NA \\
Wood & 16.5 & NA & 6.0 & NA & 32.0 & 45.0 \\
\hline
\end{tabular}

Bossink and Brouwers (1996) identified six reasons behind waste generation and their causes in Netherland as (1) design: error in contract documents, insufficient documents availability, changes in design, adoption of wrong specifications, choice of low quality materials, unawareness of product specification, and lack of construction knowledge; (2) procurement: over and under ordering, lack of options for ordering small quantities, and use of unsuitable product; (3) materials handling: damage during transportation, unsuitable storage, and unpacked supply; (4) operation: error by trade persons or labour, equipment malfunction, extreme weather conditions, accidents, damage caused by subsequent trades, use of improper material, method for laying of foundation, and requisite quantities not fully known; (5) residual: improper cutting, over mixings, waste from implementation process, and improper packaging; and (6) others: theft and lack of onsite material management plan. Similarly, Garas, Anis and Gammal (2001) identified the dominant causes of waste in the construction industry of Egypt as late information, incomplete design, insufficient specifications, poor quality control, superfluous worker's move, unskilled team, etc.

\section{RESEARCH METHODOLOGY}

This study was conducted to quantify the material wastage in different types of building projects, and identify the factors and causes of wastage from contractors' 
perspective. A literature review did not provide much information on wastage of materials in Pakistan's construction industry, since no studies were conducted in this regard. Besides that, the contextual uniqueness of different demographics results into inconsistent material wastage patterns (Chen, Li and Wong, 2002), which demands for localised data collection. In lieu of above, the optimum way to obtain information on the construction material wastage, general factors, and their contributing causes was via personal interaction. There were different stages in which this study was undertaken; firstly, an introductory study on the topic was carried out, followed by a comprehensive literature review to identify various wasteful materials and their causes. A pilot survey was carried out to shortlist the materials and causes of waste to be included in this study while considering local construction industry. Based on the input of pilot survey, 26 materials were shortlisted based on which questions for this study were formulated.

Secondly, to achieve the basic objective, a survey was conducted using structured questionnaire forms to quantify material wastage and ranking the causes identified from the literature. The questionnaire was divided into two sections; section one comprised questions about respondent's personal and professional information. Section two was further divided into three parts consisting of 48 questions in total. In the first part, respondents were asked to quantify the percentage waste of selected materials based on their experience. Then they were asked to rank the causes of wastage based on a five point Likert scale where $1=$ "very low" and 5 = "very high". Lastly, respondents were asked open ended questions regarding client and consultant behaviour in generating and controlling waste, and contractors' organisational structure and practices for waste control. It is important to note that in order to explore such subjective information based on respondents' opinions, clarify context and relevant issues, and elicit complete information, the freedom to probe in the form of face-to-face semi-structured interviews is essential (Barriball and While, 1994). Therefore, this technique was adopted throughout data collection but primarily for the last part where causes of waste generation along with their control practices were investigated. For this, different interview guides from similar studies were explored and studied. This semi-qualitative technique uses a naturalistic approach that seeks to understand phenomena in context-specific settings (Golafshani, 2003).

As a result, a total of 38 respondents were engaged who represent various contracting organisations registered under categories C-A and C-B (large); C-1, C-2, C-3, and C-4 (medium); and C-5, C-6, and below (small), with Pakistan Engineering Council (PEC), which is a national regulatory authority for licensing of operating and constructing firms.

To contextualise the study, construction professionals were consulted to shortlist the materials identified in literature review. For this purpose, a pilot survey was carried out involving a total 6 professional engineers having over 10 years of individual experience. Similarly, factors and causes of waste generation were contextualised as shown in Table 2. The shortlisted materials were bricks, wood, plaster from mortar, steel rebars, tiles, glass, paint, aluminium profile (for windows, doors and frames), bitumen, wires and cables, ceramics, marble, metals, steel railings, mild steel sections, mild steel galvanised iron (GI) pipes, water proofers, diesel, plain cement concrete (PCC), polythene sheets, anti-termites, reinforced cement concrete (RCC), plastic pipes, natural rock, thermopore sheets, and ceiling boards. 
Table 2. Shortlisted Factors and Causes of Waste Generation

\begin{tabular}{cll}
\hline Sr. No & \multicolumn{1}{c}{ Factors } & \multicolumn{1}{c}{ Causes } \\
\hline 1 & Management & Poor supervision \\
2 & & Lack of management \\
3 & & Lack of waste reduction plan \\
4 & & Absence of site waste manager \\
\hline 5 & Operation & Rework \\
6 & & Weather \\
7 & & Accidents \\
8 & & Improper worker's skill \\
9 & & Equipment malfunction \\
\hline 10 & Design & Changes in design \\
11 & & Error in contract documents \\
\hline 12 & Handling & Improper packaging \\
13 & & Storage \\
14 & & Cutting \\
15 & & Transportation \\
\hline 16 & Procurement & Ordering error \\
17 & & Supply error \\
\hline 18 & Other & Poor quality control \\
19 & & Theft/vandalism \\
\hline
\end{tabular}

To determine the sample size, Baker, Edwards and Doidge (2012) was referred for sufficient number of interviews in a qualitative analysis. Brannen (2004) suggests that there is no rule of thumb for number of interviews. Ambert et al. (1995) propose a sample of roughly 30; it has the advantage of enquiring a small number of people without forcing the hardship of unending information gathering, particularly when there are time and resource constraints. Bryman (2004) mentions the minimum number of interviews between 20 and 30. Therefore, following Porter's (1990) methodology, also adopted by Öz (2001) previously, a sample size of 38 experts with an average of 12 years of experience was adopted.

Material wastage is not very well understood by majority of stakeholders, making data collection a challenging task. However, care was taken to ensure that the interviewees selected for this study possess a better knowledge to provide meaningful conclusions. Furthermore an introduction to material wastage was provided in the first part of questionnaire. Bell (2014) argued that personally distributing the questionnaire to respondents have many advantages as good understanding of the research purpose can be achieved and difficulties can be discussed and resolved easily via face-to-face communication. Therefore, different types of building contractors were personally visited across various cities of Pakistan including Rawalpindi, Islamabad, Lahore, Karachi, Peshawar, Gujranwala, Jhelum, Faisalabad, Sargodha, Rahimyar khan, Muslim Bagh (Qila Saifullah), and Kalabagh. The interview participants were $16 \%$ quantity surveyors, $18 \%$ project managers, $29 \%$ site/planning engineers, $5 \%$ general managers, $24 \%$ owners, and $8 \%$ construction managers. The respondents were working on different types of building projects including commercial, residential, and industrial. 
Detailed analysis of collected data was conducted for statistical validation. For this purpose, widely and most understandable software for statistical and descriptive analyses were used. An advantage offered by these software is their capability to perform error-free analysis for a large amount of data (Gaur and Gaur, 2006). Particularly, MS Excel 2010 was used for descriptive and comparative analysis, and statistical tests such as reliability and normality were conducted using SPSS version 18.0. A comparative analysis was also conducted using ANOVA to observe the variance between wastages by small, medium, and large contracting firms.

\section{RESULTS AND DISCUSSIONS}

The Cronbach's a value of 0.82 confirms that the data are highly reliable (Hinton, McMurray and Brownlow, 2014). Moreover, it is found that the data are nonparametric and not normal but significant $(p<0.05)$ as per Kalmogrov-Smirnov (Justel, Peña and Zamar, 1997).

\section{Waste of Materials}

The results reveal significant variations in waste generation for some materials such as bricks (2\%-12\%), wood (2\%-15\%), and PCC (1\%-10\%). The diverse range of wastage is partially due to variation in applied technology and construction practices from contractor to contractor. The findings reveal that on average bricks are the most wasteful material at a rate of $6.82 \%$ followed by tiles $(6.68 \%)$ and plaster from mortar $(6.63 \%)$. On the other hand, anti-termites (2.92\%), water proofers (2.61\%), and diesel $(2.34 \%)$ were found to be the least wasteful material. Mean values and relative importance for all the materials were derived using MS Excel 2010. The selected materials are ranked according to their mean percentage wastage as shown in Table 3.

Table 3. Results for Wastage of Materials and Their Ranking on Pakistani Sites

\begin{tabular}{lcclcc}
\hline Materials & \% Waste & Rank & \multicolumn{1}{c}{ Materials } & \% Waste & Rank \\
\hline Bricks & 6.82 & 1 & Aluminium & 4.74 & 14 \\
Tiles & 6.68 & 2 & Plain cement concrete & 4.39 & 15 \\
Plaster from mortar & 6.63 & 3 & Marble & 4.37 & 16 \\
Wood & 6.41 & 4 & Ceiling boards & 4.32 & 17 \\
Paints & 6.00 & 5 & Bitumen & 4.29 & 18 \\
Ceramics & 5.51 & 6 & Natural Rocks & 4.14 & 19 \\
Wires and cables & 5.34 & 7 & Steel railings & 4.00 & 20 \\
Reinforced cement & 5.16 & 8 & Metals & 3.61 & 21 \\
Concrete & & & & & \\
Thermopore sheets & 5.16 & 9 & Mild steel Gl pipes & 3.57 & 22 \\
Plastic pipes & 4.95 & 10 & Mild steel sections & 3.41 & 23 \\
Glass & 4.92 & 11 & Anti-termites & 2.92 & 24 \\
Polythene sheets & 4.89 & 12 & Water proofers & 2.61 & 25 \\
Steel rebars & 4.76 & 13 & Diesel & 2.34 & 26 \\
\hline
\end{tabular}


Few findings in this research tend to support the results of earlier studies. Babatunde (2012) ranked bricks at top while performing quantitative assessment of transit waste on building sites of Abuja municipal, Nigeria. Though this study used only questionnaire survey for data collection, the general methodology followed by both studies is comparable. Nevertheless, from percentage waste point of view, the two studies do not concur; wastage of brick is reported as $6.82 \%$ in current study, in contrast to $14.15 \%$ reported by Babatunde (2012). In addition, despite the difference in sample size for a study performed by Formoso et al. (2002), where a total of 69 building sites were observed in 12 different Brazilian states, the findings of this study support the conclusion that plaster from mortar is the most wasteful material. However, comparing the percentage waste, it is found that the previous study reported an average rate of $32.7 \%$ to $46.8 \%$ compared to $6.63 \%$ reported by current study. Other than sample size and percentage waste variation, both studies follow similar methodology of opinion-based data collection along with observations using questionnaire forms and personal interviews, and thus are analogous. Nonetheless, the difference in percentage waste obtained by current study and previous studies is on account of differences of method, technology, and operations in developing or under developed regions under study.

Furthermore, a few findings did not support the previous studies; for example, in Pakistani construction industry, tiles wastage at 3rd position with an average rate of $6.68 \%$ does not concur with past research of Formoso et al. (2002), who reported an average wastage of $15.6 \%$ at 12 th rank. This lack of waste trend is not specific to the context of Pakistan but other construction industries seem to have varying patterns of percentage waste for particular materials as reported by Chen, Li and Wong (2002).

\section{Causes of Waste}

The findings reveal that most prominent macro level factor of wastage is "management" with the mean ranked value of 3.78 followed by "material handling" (3.51), "operation" (3.48), "design" (3.38), "procurement" (3.36), and other miscellaneous factors with mean value of 3.17 as shown in Figure 1.

A detailed breakdown of macro level factors into micro level causes was required for better understanding and management of wastage. It is important to understand the operational causation to help construction professionals in controlling waste. Therefore, the factors were subdivided into different causes, which were ranked by interviewees on a five point Likert scale according to their effect on wastage. The ranking of only the micro level causes is performed for better operational guidelines and insight into controlling waste rather than performing a macro level detailed investigation that could have only offered a strategic perspective into waste generation. Data was exported to MS Excel 2010 for further analysis. All the causes were ranked after finding their mean values for effect on wastage. It was observed that the most contributing cause of material wastage is "improper worker's skill" with mean value of 4.08 followed by "poor supervision" (4.0) and "lack of management" (3.81). The causes that contribute relatively less are "theft/vandalism" and "accidents" with mean values of 2.66 and 2.74 , respectively, as shown in Table 4. 


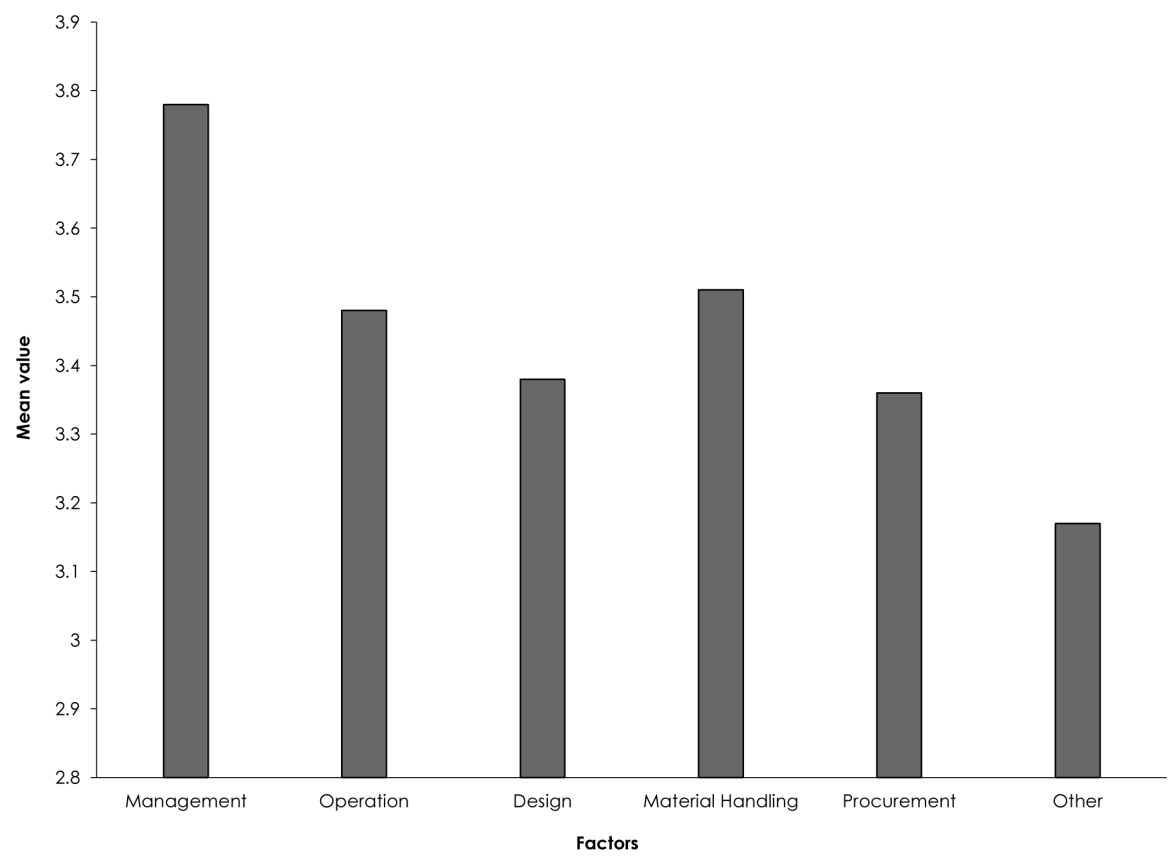

Figure 1. Factors Contributing to Waste on Pakistani Sites

Table 4. Results for Causes of Wastage on Pakistani Sites

\begin{tabular}{cllcc}
\hline Serial \# & \multicolumn{1}{c}{ Factors } & \multicolumn{1}{c}{ Causes } & Mean Value & Rank \\
\hline 1 & Management & Poor supervision & 4.00 & 2 \\
2 & & Lack of management & 3.81 & 3 \\
3 & & Lack of waste reduction plan & 3.71 & 5 \\
4 & & Absence of site waste manager & 3.61 & 10 \\
\hline 5 & \multirow{2}{*}{ Operation } & Rework & 3.47 & 11 \\
6 & & Weather & 3.31 & 14 \\
7 & & Accidents & 2.74 & 18 \\
8 & & Improper worker's skill & 4.08 & 1 \\
9 & & Equipment malfunction & 3.79 & 4 \\
\hline 10 & Design & Changes in design & 3.66 & 9 \\
11 & & Error in contract documents & 3.10 & 17 \\
\hline 12 & Handling & Improper packaging & 3.45 & 12 \\
13 & & Storage & 3.71 & 6 \\
14 & & Cutting & 3.66 & 8 \\
15 & & Transportation & 3.23 & 16 \\
\hline 16 & Procurement & Ordering error & 3.45 & 13 \\
17 & & Supply error & 3.26 & 15 \\
\hline 18 & Other & Poor quality control & 3.68 & 7 \\
19 & & Theft/vandalism & 2.66 & 19 \\
\hline
\end{tabular}


As a comparative analysis with previous research, it can be observed that "poor supervision" and "improper worker's skill" were also most prominent causes of material wastage as per Ameh and Daniel (2013) who collected data from 56 respondents using questionnaire survey in the construction industry of Nigeria. On the other hand, "theft/vandalism", which was the most significant cause in Nigerian construction industry (Babatunde, 2012), has been ranked as the least significant cause for waste generation in construction industry of Pakistan.

\section{Comparison of Material Waste and Building Type}

This study identified that the four most wasteful materials in all types of building projects were bricks, paints, plaster from mortar, and tiles. These materials were ranked top among all other building materials. A comparative study of topmost materials was done on the basis of building types and the trend analysis is shown in Figure 2.

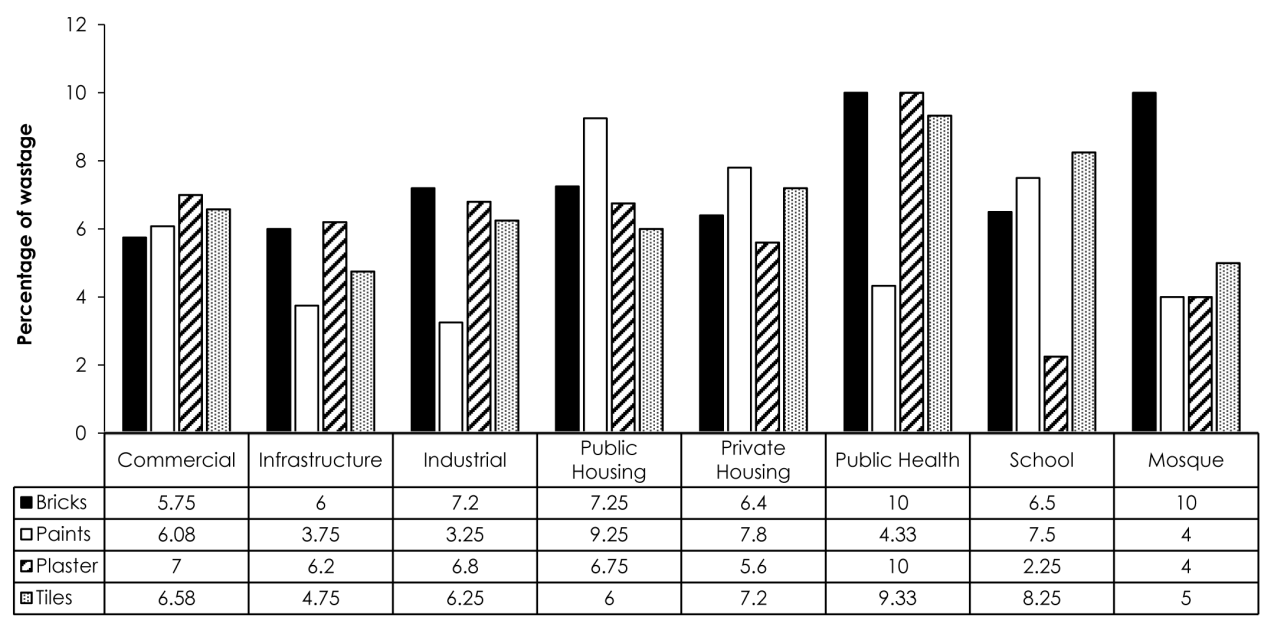

Figure 2. Materials with High Valved Wastage on Pakistani Sites

It is observed that bricks are the most wasteful material in "public health" and "mosque" projects. Owing to larger quantum of architectural detailing, which involves cutting, carving, chipping, and chiselling of brick and stone for arches, domes, and other intricate architectural members, a significant amount of waste is generated. Likewise, the elaborate architectural detailing of mosque construction results into a lot of brickwork causing considerable wastage. Similarly, in public health buildings, partitions and walls are large in number resulting into major masonry works producing more wastage of bricks. Furthermore, it is observed that paints are most wasteful in "private and public housing" projects due to the fact that housing construction involves larger colour palette for better architectural styling. In addition, a variety of paints is used for different building elements; for example, weather coating for exterior surfaces, distemper for interior, and enamel for kitchen. The problem is further aggravated due to leftover paints caused by available packaging, which is inconsistent with the requirements of smaller and medium sized buildings. 
It is also observed that plaster and tiles are the most wasteful materials in construction of "public health" projects. Hospitals and care centres are usually major projects under the category of public health and they account for substantial tiling and masonry works. By virtue of larger scope of work, more wastage of plaster from mortar and tiling works is caused.

A comparative study of the top ranked causes of waste was also done on the basis of collected data, as shown in Figure 3. The four top ranked causes in construction industry of Pakistan are "improper worker's skill", "poor supervision", "equipment malfunction", and the "lack of management".

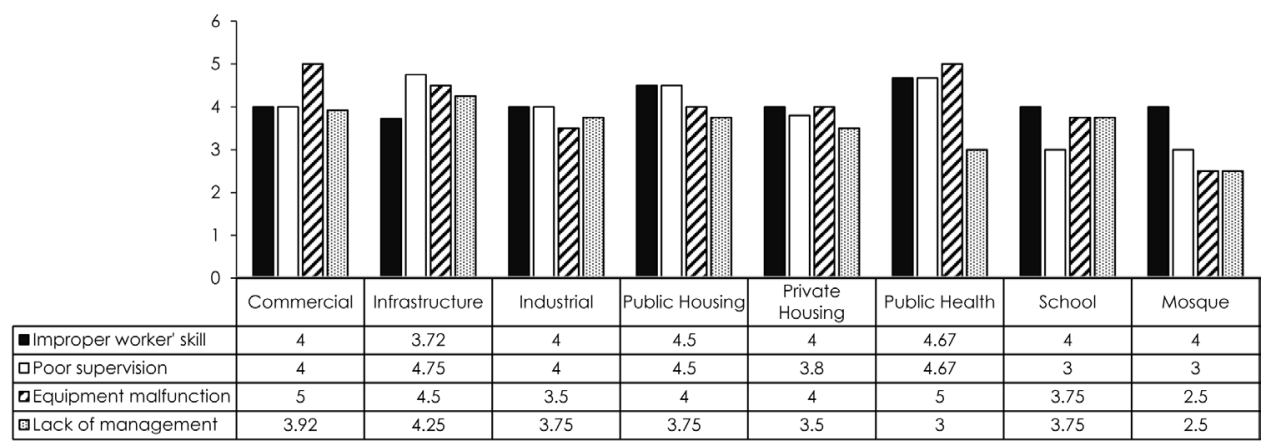

Figure 3. Causes with Maximum Contribution to Waste on Pakistani Sites

It can be observed that "improper worker's skill" is the most contributing cause of wastage in "public housing" and "public health" projects. The high wastage is due to more architectural and diverse works in these projects and unfamiliarity of labour. This points to the prevalence of contingent labour in the construction industry of Pakistan, that are daily wage earners and usually do not undergo formal technical training.

Equipment malfunction is the major cause of wastage in "public health", "infrastructure", and "commercial" projects. These projects usually have larger work scope that causes more wear and tear to tools and equipment resulting into malfunction. In infrastructure projects, major causes of waste are "poor supervision", "lack of management", and "equipment malfunction" as these projects are widely spread and have more quantity of work. Wastage occurs mostly due to poor supervision and lack of management.

Another comparative analysis of top ranked materials on the basis of contractor size (small, medium or large) is shown in Figure 4.

The analysis reveals that there is no significant variance between the three groups of contractors categorised as per their size. The variance lies between the range of $4.3 \times 10^{-4}$ for wires and cables to $4.8 \times 10^{-6}$ for water proofers. In explanation, this points towards rather lethargic and traditional management practices adopted in the construction industry of Pakistan. Specifically, the larger companies that can afford to employ modern management techniques and should demonstrate better performance in context of waste control still resort to ineffective methods and generate almost equal amount of waste as compared to small contractors. This is to be noted that simple averages for three contractor categories presented in Table 4 are rather weighted averages. Therefore, average of these three categories 
is not comparable with the total average of all the respondents, as the numbers of respondents in each category are not even.

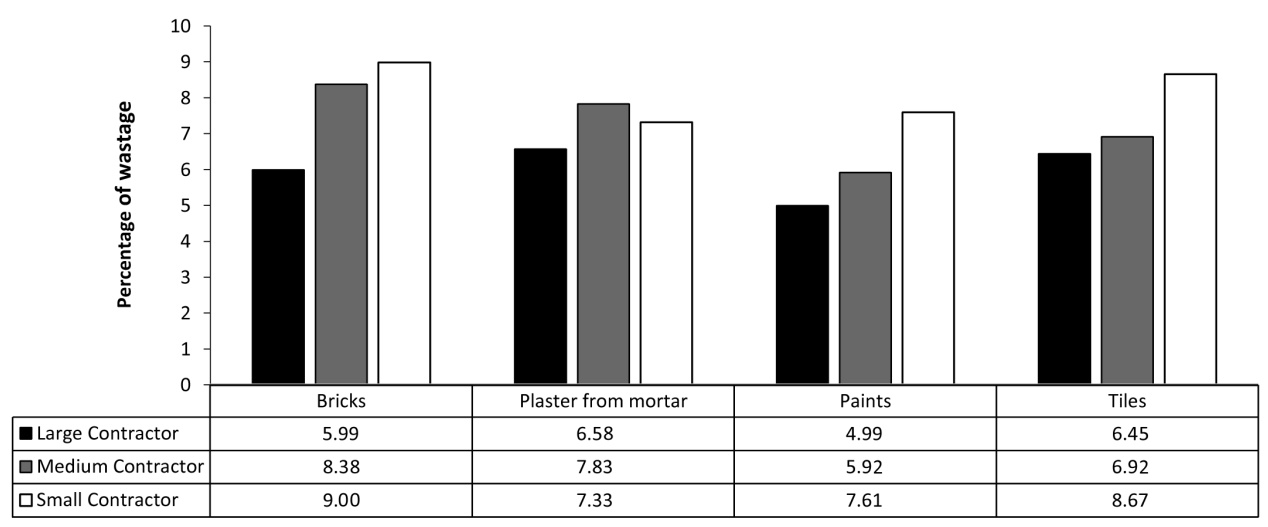

Figure 4. Materials Wastage with Respect to Contractor Size

Additionally, in the context of top four most wasteful materials, the amount of material wastage seems to decrease as contracting firm size increases. It is opportune to underline that the trend is very marginal. Smaller contractor firms have comparatively more wastages for these materials as compared to their medium and large counterparts. This trend is because the tendency of smaller contractors to compromise on workmanship and lack in experienced supervision. Despite the fact that they are mostly engaged in minor construction and repair works, and their individual contribution to waste generation is high, collectively small contracting firms have less significant waste footprint. In contrast, larger contractor firms own sophisticated tools and equipment, and engage competent site supervision ensuring better and efficient construction practices. Even then it seems that waste generation is not sufficiently and successfully controlled. However, it is opportune to state that despite lower individual contribution, large and medium contracting organisations benefit from even better waste control strategies owing to the larger volumetric consumption of construction material.

\section{CONCLUSIONS}

Material wastage occurs more in architectural work as compared to structure works, which is evident by the most wasteful materials being bricks, tiles, plaster, paints, and wood. On the other hand, diesel, anti-termites, and water proofers are the least wasteful. The factors behind this waste generation are flaws in management, material handling, and operation, which are rooted into improper worker's skill, poor supervision, and lack of management in building construction industry of Pakistan.

Material type and their percentage wastage and causes vary with types of building projects. Not every type is responsible for same amount of waste generation. Building types rich in architectural details account for more waste. It is evident from 
the collected data, highlighted in Table 4, that most waste is generated due to improper skills of workers (labourers and masons), along with poor site supervision by foremen and lack of waste management planning by engineers. It also suggests that procurement officers contribute in the cause by procuring faulty equipment increasing the overall waste generation. Clients and consultants have substantial influence on waste generation as improper design and specifications, change orders, and rework are major causes of material wastage. Finally, the size of contracting firms does influence waste generation.

Based on results and suggestions from the interviewees, few recommendations are made that will help reduce material wastage in building construction projects and enhance the efficiency of Pakistani construction industry. A full-time waste manager/supervisor on large projects can help minimise wastage. Therefore, it is suggested to include waste manager in typical organisational structure who will be responsible for usage of proper tools and techniques such as preparing and maintaining schedule of materials at start of the project and monitoring it throughout its execution, arranging proper storage places for materials, and using proper formwork. Proper training, use of technologically advanced equipment, and hiring of skilled operatives can further reduce material wastage. Finalising the project design to reduce the chances of rework and implementing a waste reduction plan from start of the project can be an effective way for waste control.

In the past, there was no related research on construction material wastages in Pakistan's construction industry; this study provides a start-up for further research that could disclose more potential statistics to minimise the loss of materials. A thorough data collection with the help of objective measurements on construction sites or dumping sites such as landfills will enhance the research impact. The results and findings of this study by comparative analysis of different types of buildings and pattern of wastage among different sizes of contractors give a new perspective on sustainable construction. The results may lead construction managers to understand actual situation of construction waste and devise ways to control it.

\section{ACKNOWLEDGEMENTS}

Special gratitude is extended to all the industrial practitioners who responded to and contributed their valuable input in the research process. The feedback given by the esteemed editor and reviewers is fully acknowledged. Authors are immensely grateful for the comments and suggestion on the earlier version of the manuscript, without which improvement would not have been possible.

\section{REFERENCES}

Ambert, A.-M., Adler, P.A., Adler, P. and Detzner, D.F. (1995). Understanding and evaluating qualitative research. Journal of Marriage and the Family, 57(4): 879-893. https://doi.org/10.2307/353409

Ameh, O.J. and Daniel, E.I. (2013). Professionals' views of material wastage on construction sites and cost overruns. Organization, Technology \& Management in Construction: An International Journal, 5(1): 747-757. 
American Institute of Architects (AIA) Sustainability Discussion Group. (2008). Quantifying sustainability: A study of three sustainable building rating systems and the AIA position statement. Available at: https://www.iccsafe.org/gr/ Documents/GreenToolkit/Quantifying_Sustainability-AIA.pdf [Accessed on 20 September 2016].

Arnold, J.R.T., Chapman, S.N. and Clive, L.M. (2012). Introduction to materials management. Upper Saddle River, NJ, USA: Pearson Prentice Hall.

Babatunde, S.O. (2012). Quantitative assessment of construction materials wastage in the Nigerian construction sites. Journal of Emerging Trends in Economics and Management Sciences, 3(3): 238-241.

Baker, S.E., Edwards, R. and Doidge, M. (2012). How many qualitative interviews is enough?: Expert voices and early career reflections on sampling and cases in qualitative research. Available at: http://eprints.ncrm.ac.uk/2273/ [Accessed on 20 September 2016].

Barriball, K.L. and While, A. (1994). Collecting data using a semi-structured interview: A discussion paper. Journal of Advanced Nursing, 19(2): 328-335. https://doi. org/10.1111/j.1365-2648.1994.tb01088.x

Begum, R.A., Siwar, C., Pereira, J.J. and Jaafar, A.H. (2006). A benefit-cost analysis on the economic feasibility of construction waste minimisation: The case of Malaysia. Resources, Conservation and Recycling, 48(1): 86-98. https://doi. org/10.1016/j.resconrec.2006.01.004

Bell, J. (2014). Doing your research project: A guide for first-time researchers. Berkshire, UK: McGraw-Hill Education.

Bossink, B. and Brouwers, H. (1996). Construction waste: Quantification and source evaluation. Journal of Construction Engineering and Management, 122(1): 55-60. https://doi.org/10.1061/(ASCE)0733-9364(1996)122:1(55)

Brannen, J. (2004). Working qualitatively and quantitatively. In C. Seale, G. Gobo, J.F. Gubrium and D. Silverman (eds.). Qualitative research practice (part 4). Thousand Oaks, California: Sage Publications, 312-326. https://doi. org/10.4135/9781848608191.d25

Bryman, A. (2004). Social research methods. New York: Oxford University Press Inc.

Chen, Z., Li, H. and Wong, C.T. (2002). An application of bar-code system for reducing construction wastes. Automation in Construction, 11(5): 521-533. https://doi.org/10.1016/S0926-5805(01)00063-2

Division of Technology, Industry and Economics (DTIE). (2009). Buildings and climate change: A summary for decision makers. Paris: UNEP DTIE Sustainable Consumption and Production Branch.

EC Harris LLP. (2013). Supply chain analysis into the construction industry - A report for the construction industrial strategy. BIS Research Paper (145). UK: Department for Business Innovation and Skills. Available at: https://www.gov. uk/government/uploads/system/uploads/attachment_data/file/252026/bis13-1 168-supply-chain-analysis-into-the-construction-industry-report-for-theconstruction-industrial-strategy.pdf [Accessed on 19 September 2016].

Ekanayake, L.L. and Ofori, G. (2004). Building waste assessment score: Design-based tool. Building and Environment, 39(7): 851-861. https://doi.org/10.1016/j. buildenv.2004.01.007

Enshassi, A. (1996). Materials control and waste on building sites: Data in the study was obtained from 86 housing projects on several locations in the Gaza Strip. Building Research and Information, 24(1): 31-34. https://doi. org/10.1080/09613219608727495 
Enshassi, A., Al-Hallaq, K. and Mohamed, S. (2006). Causes of contractors' business failure in developing countries: The case of Palestine. Journal of Construction in Developing Countries, 11 (2): 1-14.

Foo, L.C., Rahman, I.A., Asmi, A., Nagapan, S. and Khalid, K.I. (2013). Classification and quantification of construction waste at housing project site. International Journal of Zero Waste Generation, 1 (1): 1-4.

Formoso, C.T., Isatto, E.L. and Hirota, E.H. (1999). Method for waste control in the building industry. Paper presented at the Seventh Annual Conference of the International Group for Lean Construction (IGLC-7). Barkeley, CA, USA, 26-28 July 1999.

Formoso, C.T., Soibelman, L., De Cesare, C. and Isatto, E.L. (2002). Material waste in building industry: Main causes and prevention. Journal of Construction Engineering and Management, 128(4): 316-325. https://doi.org/10.1061/ (ASCE)0733-9364(2002) 128:4(316)

Garas, G.L., Anis, A.R. and Gammal, A.E. (2001). Materials waste in the Egyptian construction industry. Paper presented at the 9th Annual Conference of the International Group for Lean Construction. Singapore, 6-8 August 2001.

Gaur, A.S. and Gaur, S.S. (2006). Statistical methods for practice and research: A guide to data analysis using SPSS. Thousand Oaks, California: Sage Publications.

Golafshani, N. (2003). Understanding reliability and validity in qualitative research. The Qualitative Report, 8(4): 597-606.

Haseeb, M., Xinhailu, Bibi, A. and Rabbani, W. (2011). Hazard risk analysis and management in construction sector of Pakistan. International Journal of Economics and Research, 2(4): 35-42.

Hinton, P.R., McMurray, I. and Brownlow, C. (2014). SPSS explained. East Sussex, England: Routledge Inc.

Justel, A., Peña, D. and Zamar, R. (1997). A multivariate Kolmogorov-Smirnov test of goodness of fit. Statistics \& Probability Letters, 35(3): 251-259. https://doi. org/10.1016/S0167-7152(97)00020-5

Khanh, H.D. and Kim, S.Y. (2014). Evaluating impact of waste factors on project performance cost in Vietnam. KSCE Journal of Civil Engineering, 18(7): 19231933. https://doi.org/10.1007/s12205-014-1219-2

Koskela, L. (1992). Application of the new production philosophy to construction. Stanford, CA: Stanford University.

Kulatunga, U., Amaratunga, D., Haigh, R. and Rameezdeen, R. (2006). Attitudes and perceptions of construction workforce on construction waste in Sri Lanka. Management of Environmental Quality: An International Journal, 17(1): 5772. https://doi.org/10.1108/14777830610639440

Lee, J.H. and Lee, G.G. (2013). Assessing the environmental impact of greenhouse gases in a low-carbon green city in South Korea. KSCE Journal of Civil Engineering, 17(2): 320-327. https://doi.org/10.1007/s12205-013-1994-1

Li, H., Chen, Z., Yong, L. and Kong, S.C. (2005). Application of integrated GPS and GIS technology for reducing construction waste and improving construction efficiency. Automation in Construction, 14(3): 323-331. https://doi. org/10.1016/j.autcon.2004.08.007

Mcdonald, B. and Smithers, M. (1998). Implementing a waste management plan during the construction phase of a project: A case study. Construction Management and Economics, 16(1): 71-78. https://doi.org/10.1080/01446 1998372600 
Nagapan, S., Abdul Rahman, I. and Asmi, A. (2011). A review of construction waste cause factors. Proceedings of the Asian Conference of Real Estate: Sustainable Growth Managing Challenges (ACRE). Johor Bahru, Malaysia, 3-5 October 2011.

Nasaruddin, F.H.M., Ramli, N.H.M. and Ravana, S.D. (2008). E-construction waste exchange in Malaysia: A preliminary study. Paper presented at the 2008 International Symposium on Information Technology. Kuala Lumpur, 26-28 August 2008. https://doi.org/10.1109/ITSIM.2008.4631883

Öz, Ö. (2001). Sources of competitive advantage of Turkish construction companies in international markets. Construction Management and Economics, 19(2): 135-144. https://doi.org/10.1080/01446190010009988

Polat, G. and Ballard, G. (2004). Waste in Turkish construction: Need for lean construction techniques. Paper presented at the Proceedings of the 12th Annual Conference of the International Group for Lean Construction IGLC12. Helsingør, Denmark, 3-5 August 2004.

Poon, C., Ann, T. and Ng, L. (2001). On-site sorting of construction and demolition waste in Hong Kong. Resources, Conservation and Recycling, 32(2): 157-172. https://doi.org/10.1016/S0921-3449(01)00052-0

Porter, M.E. (1990). The competitive advantage of notions. Harvard Business Review, 68(2): 73-93.

Saidu, I. and Shakantu, W. (2015). A relationship between quality-of-estimating, construction material waste generation and cost overrun in Abuja, Nigeria. Fourth Construction Management Conference. Nelson Mandela Metropolitan University, Port Elizabeth, South Africa, 30 November - 1 December 2015, 95-104,

Sharma, A., Saxena, A., Sethi, M., Shree, V. and Varun. (2011). Life cycle assessment of buildings: A review. Renewable and Sustainable Energy Reviews, 15(1): 871-875. https://doi.org/10.1016/j.rser.2010.09.008

Shen, L., Tam, V.W., Tam, C. and Drew, D. (2004). Mapping approach for examining waste management on construction sites. Journal of Construction Engineering and Management, 130(4): 472-481. https://doi.org/10.1061/(ASCE)07339364(2004) 130:4(472)

Soibelman, L. (1993). As perdas de materiais na construção de edificações: sua incidência e seu controle. MSc. diss., The Federal University of Rio Grande do Sul.

Tam, V.W., Shen, L. and Tam, C. (2007). Assessing the levels of material wastage affected by sub-contracting relationships and projects types with their correlations. Building and Environment, 42(3): 1471-1477. https://doi.org/ 10.1016/j.buildenv.2005.12.023 